\title{
Higher Prevalence of Undiagnosed Diabetes in Urban Adult Indian Population than in South Asians Living in the United Kingdom
}

\author{
Raja Selvarajan ${ }^{1, *}$, Satyan M Rajbhandari², K Vijay Kumar ${ }^{1}$ \\ ${ }^{1}$ Diabetacare India, Consultant Physician and Diabetologist, Bangalore, 560034, Karnataka, India \\ ${ }^{2}$ Lancashire Teaching Hospital, Consultancy Physician and Honorary Clinical Professor, United Kingdom
}

Received January 6, 2021; Revised March 22, 2021; Accepted April 18, 2021

\section{Cite This Paper in the following Citation Styles}

(a): [1] Raja Selvarajan, Satyan M Rajbhandari, K Vijay Kumar, "Higher Prevalence of Undiagnosed Diabetes in Urban Adult Indian Population than in South Asians Living in the United Kingdom," Advances in Diabetes and Metabolism, Vol. 9, No. 1, pp. 1 - 5, 2021. DOI: 10.13189/adm.2021.090101.

(b): Raja Selvarajan, Satyan M Rajbhandari, K Vijay Kumar (2021). Higher Prevalence of Undiagnosed Diabetes in Urban Adult Indian Population than in South Asians Living in the United Kingdom. Advances in Diabetes and Metabolism, 9(1), 1 - 5. DOI: 10.13189/adm.2021.09001.

Copyright $\bigcirc 2021$ by authors, all rights reserved. Authors agree that this article remains permanently open access under the terms of the Creative Commons Attribution License 4.0 International License

\begin{abstract}
Background: Type 2 diabetes mellitus (T2DM), a metabolic disorder with high levels of glucose due to absolute insulin deficiency or relative insulin deficiency (insulin resistance) affects about 20 percent of adults in South Asia (SA) in the United Kingdom (UK). This is similar to that of urban Indian population, where the incidence is about 15 percent. Despite this, there is a scarcity of data comparing SA with that of the Indian urban community in the UK. Objective: The aim of the present study was to study the prevalence and differences of undiagnosed diabetes and associated risk factors between the urban adult Indian populations living in Bangalore and in South Asians residing in the UK. Materials and Methods: The general publics above age of 30 (adult) were encouraged to come for general checkup including capillary blood glucose test during public health events held at various town halls in UK. In the UK, nearly 230 SA adults were screened at 3 separate events held in Preston, Bolton and London. While in Bangalore, at 4 events were held at mosques and the community centres and 412 adult subjects were tested. Subjects known to have diabetes (DM) were analyzed separately from those that were not known to have diabetes (non-DM. Clinical monitoring of anthropometric data and random levels of capillary blood glucose were analyzed. Results: We found that $14.6 \%$ and $42.7 \%$ of subjects had previously documented diabetes in the UK and India, respectively $(\mathrm{P}<0.001)$. No characteristic
\end{abstract}

differences in age and BMI were found between the subjects of SA in the UK and those in India. In Bangalore, more men $(69 \%)$ attended screening programme compared to the UK (14.6 percent). Of people without history of diabetes $30.1 \%$ of Indians in urban Bangalore had elevated blood sugar in comparison to SA in the UK (10.8\%). Conclusion: There is an urgent need to perform screening of adult population for diabetes in urban India, where almost $20 \%$ people have impaired glucose tolerance.

Keywords Diabetes, Insulin Resistance, South Asians, Urban Adult

\section{Introduction}

Diabetes Mellitus (DM) is metabolic disorder which involves improper elevation in blood glucose levels. DM is classified in two types i.e. Type I DM (T1DM) and Type II DM (T2DM). T1DM is characterized by destruction of beta cells in pancreas leading to the complete absence or very less amount of insulin. T2DM entails a more insidious onset where a functional deficiency in insulin is triggered by a discrepancy in insulin levels and insulin sensitivity. Resistances to insulin are multifactorial, and have genetic bias, but it typically expresses with obesity and ageing. The 
complications of diabetes include potential blindness, lower limb amputation, renal dysfunction, heart attack and stroke [1]. DM affects millions of people and its prevalence is increasing day-by-day [2]. In developed countries, it is projected that about $87 \%$ to $91 \%$ of registered diabetic individuals have T2DM, $7 \%$ to $12 \%$ have T1DM, while $1 \%$ to $3 \%$ have other forms of DM [3, 4]. New statistics from IDF 2019 reveal that approximately 463 million adults were living with diabetes by 2045 this will rise to 700 million. The proportion of people with type 2 diabetes is increasing in most countries. $79 \%$ of adults with diabetes were living in low-income and middle-income countries. 374 million people are at increased risk of developing T2DM [5]. While DM is one of the biggest health problems of the 21st century, most government and public health agencies remain oblivious of the current effects of this disease and its consequences [6].

There are 3.9 million persons in the UK who have been diagnosed with diabetes. 8 percent of these individuals are estimated to have type 1 diabetes and 90 percent are estimated to have type 2 and about $2 \%$ of individuals have rare type of diabetes [6]. Moreover, it is estimated that in the UK there are half a million more persons who have diabetes but have not been diagnosed yet. The growing incidence of diabetes is a significant clinical and financial threat to the health sector of the United Kingdom, with $10 \%$ of the NHS budget actually spending on diabetes, which amounts to about $£ 9$ billion per year [6]. Recently, it has been reported that the ethnicity of the individual poses risk for having diabetes and hence screening the target population may help in diagnosing the undiagnosed patients. In people of South Asian heritage, T2DM is up to six times more common, and the largest ethnic minority in the United Kingdom is people of South Asian (SA) ethnicity (of Indian, Pakistani and Bangladeshi descent) who in many metropolitan locations now constitute the dominant ethnic community [7]. The prevalence of diabetes in SA is $23 \%$ which is very high compared to other ethnic groups in United Kingdom (UK) [4]. It has also been predicted that the South Asian subcontinent will be having the greatest burden of diabetes worldwide by $2030[\mathbf{8 , 9}]$. The IDF has estimated that India currently has more than 77 million people with DM. The prevalence of diabetes among urban participants in India is reported to be the highest in the world $15.7 \%$ [10-11] with $27.6 \%$ of the people undiagnosed [12]. The prevention of complications of DM by controlling the blood sugar levels is an important factor to be considered in the management [13]. Because of a number of factors like less utilization or under-performance of health systems, low awareness and the often slow onset and progression of T2DM, the condition remains undiagnosed [14]. The more the patient remains undiagnosed of the condition, the more will be the risk of uncontrolled diabetes, its complications and aggravation [5]. Studies which actively screen for diabetes by measuring blood glucose levels provide estimation of undiagnosed DM. Participants who mention not having diabetes may be discovered to have it by measuring their blood glucose in certain trials and may then be identified as having 'previously undiagnosed' or 'newly diagnosed' diabetes [2]. The recruitment of research studies by SA raises big challenges for scientists. This is a crucial field that needs investment if many of the deficiencies in research found in this study are to be effectively resolved. The lack of proper coding for ethnicity and language in most primary care datasets is a significant impediment, and further effort is required to promote routine ethnicity coding in primary care. It has been proposed that SA are less likely to volunteer to engage in clinical trials; and this might also be one of the reasons for tremendous increase in DM population in such regions including UK and SA [15]. Notwithstanding this, there is paucity of data comparing SA in the UK with those of urban Indian population. Hence, considering all these scenarios, in order to ascertain the prevalence of undiagnosed diabetes mellitus patients in our environment, a study was designed to see variations in the characteristics of patients among SA living in the UK and urban Indian population from Bangalore.

\section{Materials and Methods}

\subsection{Subjects}

The present study was the observational study conducted among the sample of patients obtained from four different locations (at Preston, Bolton, London in the UK and Bangalore in India) through convenient sampling technique. The study was done as per the guidelines with prior permission from patients. The general public was encouraged to come for regular health check up, including capillary blood glucose checks at three public health events held in Preston, Bolton and London in the UK, where medical students undertook screening. Similarly, four health check-up exercises were carried out by staffs of Diabetacare in mosques and community centres in Bangalore. Invitations were sent by advertisements in local newspapers, circulation of pamphlets in public places and word of mouth for these activities. Thus, inclusion criteria for subjects included in UK were 1) Persons attending the public health events held at various town halls 2) Age of 30 years 3) Belonging to South Asian descent (individuals originating from India, Pakistan, Nepal, Sri Lanka and Bangladesh 4) Consenting to be included in the study. An exclusion criterion was refusal for consent. Similarly, in India the inclusion criteria were (i) People attending the health check-up camps organized at mosque and community centers in urban area of Bangalore (ii) Age more than 30 years (iii) Consenting to be included in the study. An exclusion criterion was refusal for consent.

\subsection{Clinical Methods}

All the subjects were included in the study after taking informed written consent. Simple history, anthropometric 
data, blood pressure and random blood glucose (RBS) were measured among the study subjects. The results and RBS levels were made available to them and those who had abnormal results were advised to contact their health care provider for further management.

\subsection{Diagnostic Criteria}

Subjects who reported of not having diabetes and had a blood glucose levels > 140mg/dl were said to have impaired glucose while those having blood glucose levels $>200 \mathrm{mg} / \mathrm{dl}$ were said to have possible diabetes (Undiagnosed diabetes mellitus). Patients who had blood pressure >160/90mm of $\mathrm{Hg}$ were said to have hypertension.

\subsection{Statistical Analysis}

The information thus obtained was evaluated using the statistical kit of SAS (version 9.0; SAS Institute, Inc., Cary, $\mathrm{NC}$ ). The significance of degree was taken as p-value $<0.001$

\section{Results}

In UK, 230 subjects of SA origin were screened at 3 events held at Preston, Bolton and London. In Bangalore, 412 subjects were screened at 4 events held at mosques and the community center. Subjects known to have diabetes (DM) were analyzed independently from those that were not known to have diabetes (non-DM).Table 1 and 2 give the summary data.

Table 1. Demographic data of the subjects

\begin{tabular}{|c|c|c|c|}
\hline Parameters & $\begin{array}{c}\text { UK } \\
(\mathrm{n}=230)\end{array}$ & $\begin{array}{c}\text { Bangalore } \\
(\mathrm{n}=412)\end{array}$ & $\mathrm{p}$ Value \\
\hline $\begin{array}{c}\text { Age } \pm \text { SD } \\
(\text { Years })\end{array}$ & $53.9 \pm 13.4$ & $49.3 \pm 10.9$ & NS \\
\hline $\begin{array}{c}\text { Height } \pm \text { SD } \\
(\mathrm{cm})\end{array}$ & $162 \pm 12.1$ & $89.7 \pm 39.7$ & \\
\hline $\begin{array}{c}\text { Weight } \pm \text { SD } \\
(\mathrm{kg})\end{array}$ & $75.6 \pm 39.1$ & $137.9 \pm 38.2$ & \\
\hline BMI \pm SD & $27.4 \pm 5.3$ & $28.1 \pm 5.4$ & NS \\
\hline Male (\%) & $75(38.3 \%)$ & $278(69.2 \%)$ & $<0.001$ \\
\hline
\end{tabular}

Table 2. Medical parameters of the subjects in two groups

\begin{tabular}{|l|c|c|c|}
\hline \multicolumn{1}{|c|}{ Parameters } & $\begin{array}{c}\text { UK } \\
(\mathrm{n}=230)\end{array}$ & $\begin{array}{c}\text { Bangalore } \\
(\mathrm{n}=412)\end{array}$ & $\begin{array}{c}\mathrm{p} \\
\text { Value }\end{array}$ \\
\hline Subjects with known DM & $14.6 \%$ & $42.7 \%$ & $<0.001$ \\
\hline $\begin{array}{l}\text { Proportion of patient with } \\
\text { hypertension } \\
\text { (BP > 160/90 mm Hg) in DM }\end{array}$ & $22.7 \%$ & $52.8 \%$ & 0.01 \\
\hline $\begin{array}{l}\text { Proportion of patients with } \\
\text { Impaired Glucose (BG > 140 } \\
\text { mg/dl) amongst non-DM }\end{array}$ & $8.5 \%$ & $21.0 \%$ & $<0.01$ \\
\hline $\begin{array}{l}\text { Proportion of patients with } \\
\text { possible diabetes (BG > 200 } \\
\text { mg/dl) amongst non-DM }\end{array}$ & $2.3 \%$ & $9.1 \%$ & 0.01 \\
\hline
\end{tabular}

\section{Discussion}

In this study we investigated the comparative differences of undiagnosed diabetes in urban adult Indian populations living in Bangalore and in South Asians residing in UK. There was no characteristic difference observed between the subjects of SA in UK and those in India with regards to age and BMI. The screening included more males (69.2\%) in Bangalore, India than in the UK (38.2\%) (See table 1). This may be because of cultural differences and the fact that a number of screenings took place in mosque in Bangalore where visitors were predominantly males. The proportion of SA subjects with known diabetes who came for screening is significantly low in the UK in comparison to Indian subjects (14.6\% Vs $42.7 \%)$ despite higher prevalence there. It may be because of health system in the UK where all people with diabetes get free review and treatment. This may be the reason for low prevalence of uncontrolled hypertension in this group. There is no screening programme for detection of diabetes in the UK and in India, despite which there were more cases of undiagnosed impaired glucose tolerance $(21.0 \%)$ and possible diabetes $(9.1 \%)$ detected in India while only $8.5 \%$ cases of undiagnosed impaired glucose tolerance and $2.3 \%$ cases of possible diabetes were detected in SA in UK. Thus around $30.1 \%$ had abnormal blood sugar results which are very high as compared to SA in UK $(10.8 \%$ ) (See table 2 and Figure 1). The data showed the three-times more prevalence of undiagnosed DM in India compared to SA in the UK. 


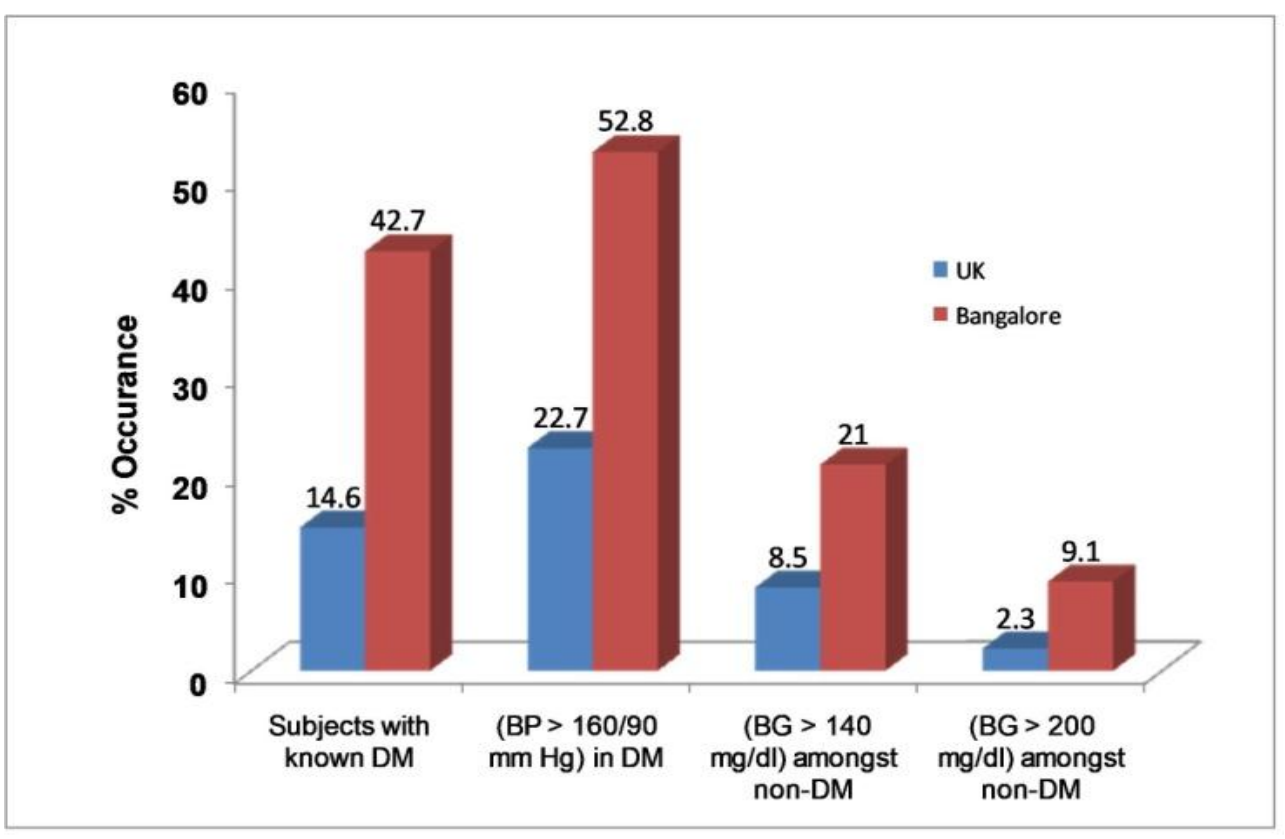

Figure 1. Comparative Medical parameters of the subjects in two groups (UK and Bangalore)

This high difference suggests that other than ethnicity various factors are responsible for undiagnosed DM. This may be because of cultural barriers among Indians which prevent them from making changes in diet (large carbohydrates fasting), body image that well health and greater standing are associated with medium to large body weights, with thinness associated with being less healthy. Urban population in India has more sedentary lifestyles compared with the general population, and engages in less physical activity [5]. Similarly, inadequate diabetes screening and prevention care, non-compliance with diabetic treatment recommendations, lack of available counseling, and long-distance travel to health services are some of the reasons associated with greater prevalence of undiagnosed DM in urban Indian communities [16]. Studies of type 2 diabetes rates in the Indian subcontinent are to some extent complicated by insufficient data and the fact that rates vary substantially in the Indian subcontinent on the basis of regional spread and socio-economic status [17]. Some research; however, indicate that risk factors linked to an urban lifestyle are significant. In reality, South Asians living in sub-continental cities have far higher rates of type 2 diabetes compared to rural populations, but rates are the as lifestyles in both rural and urban areas become more westernized [18]. So collectively socio-economic status, geographical distribution and life style adopted by the urban Indian population have great impact on the higher prevalence of undiagnosed DM. Thus, the findings of our study highlight the urgent need of screening programmes for Diabetes in urban areas for actively searching of undiagnosed diabetes patients. Limitations of the study were the bias introduced because of convenient sampling technique (urban population only, calling for
Diabetic camps may cause more patients to come who suspect of having DM rather than who do not have, RBS rather than measuring fasting and post-prandial blood glucose of the patients). However, many of the limitations are inherent in a cross-sectional epidemiological study and hence the data are therefore comparable.

\section{Conclusions}

The results of our research illustrate the critical need for urban diabetes screening services to specifically look for undiagnosed patients with diabetes. In urban India, where nearly 20 percent of people have reduced glucose tolerance, and increased incidence of Diabetes in young necessitating screening for adult population for diabetes.

\section{Conflicts of Interest}

The authors have no conflicts of interest relevant to this article to report.

\section{Funding}

None

\section{Acknowledgements}

We are very grateful to Vedant Scientific Writing Services (VSWS), Mumbai, India for writing and editing assistance of the manuscript. 


\section{REFERENCES}

[1] Kaveeshwar SA, Cornwall J. The current state of diabetes mellitus in India. The Australasian medical journal. 2014;7(1):45-48.doi: 10.4066/AMJ.2013.1979

[2] Guariguata L, Whiting DR, Beagley J, Linnenkamp U, Hambleton I and Shaw JE Global estimates of diabetes prevalence in adults for 2013 and projections for 2035 . Diabetes Res ClinPract 2013 103(2); 137 - 149.doi: 10.1016/j.diabres.2013.11.002.

[3] Okur ME, Karantas ID, Siafaka PI. Diabetes Mellitus: a review on pathophysiology, current status of oral pathophysiology, current status of oral medications and future perspectives. ACTAPharmaceuticaSciencia. 2017; 55(1):61-82. doi: 10.23893/1307-2080.APS.0555

[4] Chung IM, Rajakumar G, Subramanian U, Venkidasamy B, Khanna VG, Thiruvengadam M. Insights on the current status and advancement of diabetes mellitus type 2 and to avert complications: An overview. Biotechnology and applied biochemistry. 2019:1-9.doi: 10.1002/bab.1853.

[5] IDF2019https://www.diabetesatlas.org/en/sections/worldwi de-toll-of-diabetes.html

[6] https://www.diabetes.org.uk/professionals/position-statemen ts-reports/statistics/diabetes-prevalence-2019 Kanaya AM, Herrington D, Vittinghoff E, Ewing

[7] SK, Liu K, Blaha MJ, Dave SS, Qureshi F and Kandula NR. Understanding the high prevalence of diabetes in U.S. south Asians compared with four racial/ethnic groups: the MASALA and MESA studies. Diabetes Care. 2014; 37(6):1621-1628. doi: 10.2337/dc13-2656.

[8] Wild S, Roglic G, Green A, Sicree R and King H. Global prevalence of diabetes: estimates for the year 2000 and projections for 2030. Diabetes Care 2004; 27(5):1047-1053. doi: 10.2337/diacare.27.5.1047.

[9] Shaw JE, Sicree RA and Zimmet PZ. Global estimates of the prevalence of diabetes for 2010 and 2030. Diabetes Res ClinPract 2010;87(1):4-14.doi: 10.1016/j.diabres.2009.10.0
07.

[10] https://www.diabetesatlas.org/en/sections/demographic-andgeographic-outline.html

[11] Anjana RM, Ali MK, Pradeepa R, Deepa M, Dutta M, Unnikrishanan R, Reema $\mathrm{M}$ and Mohan $\mathrm{V}$ The need for obtaining accurate nationwide estimates of diabetes prevalence in India: rationale for a national study on diabetes. Indian J Med Res 2011; 133: 369-380.

[12] Mitra S. Diabetes Research, Prevalence, and Intervention in India. European Journal of Environment and Public Health. 2019; 3(1):em0023. doi.org/10.20897/ejeph/4004.

[13] Chaudhury A, Duvoor C, Reddy Dendi VS, Kraleti S, Chada A, Ravilla R, Marco A, Shekhawat NS, Montales MT, Kuriakose K, Sasapu A. Clinical review of antidiabetic drugs: implications for type 2 diabetes mellitus management. Frontiers in endocrinology. 2017; 8(6):1-12. doi:10.3389/fe ndo.2017.00006

[14] Perveen S, Shahbaz M, Keshavjee K, Guergachi A. Prognostic modeling and prevention of diabetes using machine learning technique. Scientific reports. 2019; 9(1):1-9.

[15] Misra A, Ramchandran A, Jayawardena R, Shrivastava U, Snehalatha C. Diabetes in south Asians. Diabetic Medicine. 2014;31(10):1153-1162. doi: 10.1111/dme.12540.

[16] Araszkiewicz A, Bandurska-Stankiewicz E, Budzyński A, Cypryk K, Czech A, Czupryniak L, Drzewoski J, Dzida G, Dziedzic T, Franek E, Gajewska D. 2019 Guidelines on the management of diabetic patients. A position of Diabetes Poland. Clinical Diabetology. 2019; 8(1):1-95. doi:10.5603/ DK.2019.0001

[17] Gregg EW, Sattar N, Ali MK. The changing face of diabetes complications. The lancet Diabetes \& endocrinology. 2016;4(6):537-547. doi: 10.1016/S2213-8587(16)30010-9

[18] Ramachandran A, Snehalatha C, Baskar AD, Mary S, Kumar CS, Selvam S, Catherine S, Vijay V. Temporal changes in prevalence of diabetes and impaired glucose tolerance associated with lifestyle transition occurring in the rural population in India. Diabetologia. 2004;47(5):860-865. doi: 10.1007/s00125-004-1387-6. 